\title{
Individual- and neighborhood-level education influences the effect of obesity on prostate cancer treatment failure after prostatectomy
}

\author{
Charnita Zeigler-Johnson ${ }^{1} \cdot K_{\text {Knashawn H. Morales }}^{2} \cdot$ Karen Glanz $^{2}$ • \\ Elaine Spangler $^{2} \cdot$ Jonathan Mitchell $^{2} \cdot$ Timothy R. Rebbeck ${ }^{2}$
}

Received: 3 March 2015/Accepted: 1 July 2015/Published online: 14 July 2015

(c) The Author(s) 2015. This article is published with open access at Springerlink.com

\begin{abstract}
Purpose The relationship between obesity and prostate cancer $(\mathrm{CaP})$ treatment failure is complex and may vary by patient- and neighborhood-level educational attainment. We evaluated whether patient- and neighborhood-level education is associated with the effect of obesity on biochemical recurrence.

Methods Seven hundred and forty-six $\mathrm{CaP}$ cases were classified into four groups: Concordant Low-Low: less educated cases ( $\leq 4$ years college) living in a less educated neighborhood (below-median proportion of college-educated residents; $n=164)$; Concordant High-High: highly educated cases ( $\geq 4$ years college) living in a highly educated neighborhood (above-median proportion of collegeeducated residents; $n=326$ ); Discordant Low-High: less educated cases living in a highly educated neighborhood
\end{abstract}

Charnita Zeigler-Johnson

charnita.zeigler-johnson@jefferson.edu

Knashawn H. Morales

knashawn@mail.med.upenn.edu

Karen Glanz

kglanz@upenn.edu

Elaine Spangler

espangle@mail.med.upenn.edu

Jonathan Mitchell

jmitch@mail.med.upenn.edu

Timothy R. Rebbeck

rebbeck@exchange.upenn.edu

1 Division of Population Science, Department of Medical Oncology, Thomas Jefferson University, Philadelphia, PA, USA

2 Center for Clinical Epidemiology and Biostatistics, University of Pennsylvania, Philadelphia, PA, USA
( $n=69)$; and Discordant High-Low: highly educated cases living in a less educated neighborhood $(n=187)$. Cox regression models were used to examine associations between obesity and biochemical (PSA) failure after prostatectomy stratified by the concordant/discordant groups.

Results The association of obesity with biochemical failure varied significantly by educational concordance/ discordance $(p=0.007)$. Obesity was associated with risk of biochemical failure for less educated cases residing in less educated neighborhoods (HR 3.72, $95 \%$ CI 1.30-10.65). The relationship was not significant for other concordant/discordant groups.

Conclusions Obesity effects on $\mathrm{CaP}$ outcomes vary by multilevel educational discordance/concordance. Strategies to decrease prostate cancer risk of progression may focus on reduction in obesity, particularly for less educated cases residing in less educated neighborhoods.

Keywords Prostate cancer - Obesity - Education - Crosslevel interaction $\cdot$ Neighborhood SES

\section{Introduction}

Prostate cancer is a major public health burden with few confirmed modifiable risk factors. Obesity, a potentially modifiable risk factor, increases the risk of advanced disease at diagnosis and treatment failure [1-5]. Obesity also varies by socioeconomic status (SES). Poorer neighborhoods are more likely to have higher levels of obesity [6, 7]. A relationship between obesity and poor prostate cancer outcomes and recurrence of prostate cancer has been supported by several reports [8-10]. However, the association between obesity and prostate cancer outcomes has been 
inconsistent [3, 9, 11-13]. Similarly, low neighborhood SES has been correlated with increasing disease rates and poorer health outcomes, including mortality [14-18].

It has been hypothesized that adverse health effects are related to living in a neighborhood with an SES that is discordant with one's own SES [19]. This phenomenon of SES discordance is also referred to as cross-level interaction [20]. Associations of SES discordance and health outcomes such as mortality, hospitalizations, and alcohol consumption have been reported [20-23]. Reasons for these effects might be that low-SES individuals in highSES neighborhoods have limited access to resources or less opportunity to maintain healthy lifestyles [20]. Individuals living in SES-discordant situations may experience differences in cancer education, access to care, and feelings of relative deprivation and stress compared with those living in SES-concordant situations [20, 24].

The goal of this study was to describe educational discordance/concordance in a population of $\mathrm{CaP}$ cases and evaluate whether associations between obesity and $\mathrm{CaP}$ severity are influenced by educational discordance/concordance.

\section{Methods}

\section{Study Sample}

A prospective study design was used to examine the relationship between discordance in educational attainment at $\mathrm{CaP}$ diagnosis and biochemical failure after radical prostatectomy. European American (EA) and AfricanAmerican (AA) $\mathrm{CaP}$ cases were recruited at the University of Pennsylvania Health System (UPHS, Philadelphia, PA) via the Study for Clinical Outcomes Risk and Ethnicity (SCORE). All cases seen in these clinics that were newly diagnosed within the previous 12 months with a histologically confirmed primary $\mathrm{CaP}$ at any stage and underwent prostatectomy for treatment of their cancer were eligible for participation in this study.

Informed consent was obtained from all individual participants included in the study under a protocol approved by the Institutional Review Board at the University of Pennsylvania. Case status was confirmed by medical records review using a standardized abstraction form. Men were excluded from this study if they reported having exposure to finasteride or dutasteride at any time prior to their $\mathrm{CaP}$ diagnosis, were diagnosed more than 12 months prior to the date of study ascertainment, or had ever been diagnosed with cancer at any site (except non$\mathrm{CaP}$ skin cancer) other than their recently diagnosed $\mathrm{CaP}$.

We used patient-level education obtained from questionnaire self-report. Patient-level education was defined as having attended $<4$ years or $\geq 4$ years of college.
Residential addresses of cases were geo-coded to the census tract level with Geographic Information Systems (ArcGIS) technology [25]. We used census tract college education variables from the 2000 US Census to measure neighborhood educational attainment. The median cutpoint $(37 \%)$ for "percent of census tract residents with college education" was determined for all cases combined. Because $68 \%$ of the SCORE sample was college-educated, we used college as the cut-point for defining educational discordance. Therefore, we evaluated the crosslevel effects of having a college education and residing in a higher or lower than average college-educated community. Educational concordance/discordance was defined as (1) less than 4 years of patient college education and residence in a neighborhood with below-median neighborhood college education attainment; (2) less than 4 years of patient college education and above-median neighborhood college education attainment; (3) four or more years of patient college education and below-median neighborhood college educational attainment; and (4) four or more years of patient college education and above-median neighborhood college education attainment. Groups 1 and 4 represent educationally "concordant groups," while groups 2 and 3 represent educationally "discordant" groups.

\section{Statistical analysis}

Univariate analyses of patient characteristics were evaluated after stratifying on concordance/discordance groups and obesity status. Non-obese was defined as body mass index (BMI) $<30 \mathrm{~kg} / \mathrm{m}^{2}$, and obese was defined as BMI $\geq 30 \mathrm{~kg} / \mathrm{m}^{2}$. Chi-square tests and Fisher's exact tests were used to compare discrete variables across obesity groups. Kruskal-Wallis tests were used to compare differences in medians of continuous variables across obesity groups. Patient characteristics measured at diagnosis included tumor grade, with low grade defined as tumor Gleason score of six or below and high grade defined as a tumor score of seven or greater; prostate-specific antigen (PSA), with low-PSA group defined as $<10 \mathrm{ng} / \mathrm{ml}$ and high-PSA group defined as PSA $\geq 10 \mathrm{ng} / \mathrm{ml}$; and age group $<$ and $\geq 60$ years.

The primary study outcome was biochemical failure after prostatectomy, defined as a PSA greater than or equal to $0.2 \mathrm{ng} / \mathrm{dl}$ after primary treatment. Cases were followed for a median 28 months (range $=2-168$ months). Cox regression models were adjusted for census tract, tumor grade, PSA at diagnosis, patient race, age, and the obesityeducational concordance/discordance interaction term. Modification of the association between obesity and biochemical failure by education was assessed by an interaction term in the Cox regression model. 


\section{Results}

We studied 227 obese and 519 non-obese incident $\mathrm{CaP}$ cases recruited into the SCORE study from 1995 to 2011 and followed for biochemical failure after treatment (radical prostatectomy and radiation) for $\mathrm{CaP}$ in the UPHS. Cases ranged in age from 39 to 79 years $(S D=6.54)$. Thirty percent of SCORE cases were obese (Table 1). Sixty-nine percent of SCORE cases were college-educated (71\% non-obese and $63 \%$ obese, $p=0.024$ ). As shown in Table 1 , the distribution of obesity was significantly different across the concordant/discordant groups $\left(\chi_{3}^{2}=15.314, p=0.002\right)$.

Among all cases, obese men were more likely than nonobese men to be AA ( 20 vs. $11 \%, p=0.002$ ), less likely to have a college education (63 vs. $71 \%, p=0.024$ ), presented with higher BMI (26.5 vs. $32.5 \mathrm{~kg} / \mathrm{m}^{2}$, $p<0.001)$ and lower PSA (4.9 vs. $5.3 \mathrm{ng} / \mathrm{ml}$ ), and more likely to have higher tumor stage ( 35 vs. $24 \%, p=0.003$ ) and grade (55 vs. $45 \%, p=0.004)$ at $\mathrm{CaP}$ diagnosis (Table 1).

Similarly, in stratified analyses, obese cases in the concordant high patient, high neighborhood education group were more likely to be AA $(p=0.043)$ and have lower PSA levels $(p=0.044)$. Obese cases in the discordant high patient, low neighborhood education group also were more likely to be African-American $(p=0.016)$ and have a high tumor grade $(p<0.001)$. BMI was consistently different by obesity status across each of the education concordance/discordance groups $(p<0.001)$.

Obese and non-obese cases in the concordant low patient, low neighborhood education group and the discordant low patient, high neighborhood education group did not differ in other demographic and clinical characteristics.

Overall, $78(10.5 \%)$ patients experienced biochemical failure during the study. Univariately, there were no differences in overall failure rates by obesity status $(p=0.068)$ or concordance/discordance groups $(p=0.827)$. However, obese cases in each concordant/discordant education group experienced a quicker time to biochemical failure $(\mathrm{CaP}$ recurrence) than non-obese cases (Fig. 1a-d). In multivariable models, the association of obesity with biochemical failure varied significantly by educational concordance/ discordance $(p=0.007)$. Obesity was significantly associated with risk of biochemical failure in the concordant low patient, low neighborhood education group (HR 3.72, $95 \%$ CI 1.30-10.65, Table 2). The HR was similar for the discordant low patient, high neighborhood education group, but the effect was not significant (HR 3.98, $95 \%$ CI 0.60-26.54).

\section{Discussion}

Our results suggest that cases of lower education living in concordant lower education neighborhoods are at the highest risk of biochemical failure if they are obese. Elevated BMI previously has been associated with increased risk of biochemical failure $[1,9,10,26]$. While the literature on SES discordance suggests that low-SES individuals living in high-SES neighborhoods may be at greatest risk of poor health outcomes or mortality, our results of a hospital-based $\mathrm{CaP}$ sample show that only obese cases living in a concordant low patient-low neighborhood education context are at particular risk of biochemical failure.

We hypothesize that obese low-education individuals living in low-education neighborhoods may experience "double jeopardy" because they are predisposed to multiple disadvantages at both the individual and neighborhood levels [22]. For CaP, living in education discordant or concordant high education contexts may neutralize risk of biochemical failure in obese cases. Similarly, either higher patient or neighborhood education may buffer risks that may impact poor $\mathrm{CaP}$ outcomes.

Several studies have examined SES cross-level effects on various health outcomes. Most have suggested that SES discordance resulted in worse health outcomes. Winkleby et al. [20] reported relationships between SES discordance and overall mortality. Death rates among low-SES men and women were highest in high-SES neighborhoods, lower in moderate-SES neighborhoods, and lowest in low-SES neighborhoods. Taylor et al. [21] extended this work to find similar associations for SES discordance. Higher hospitalization rates were observed among low-SES cases living in high-SES neighborhoods. Mulia et al. [22] reported relationships between SES discordance and high alcohol consumption, also among low-SES individuals residing in high-SES neighborhoods. Similar to our findings with biochemical failure, in a study of breast cancer cases, women with concordant low patient education and low neighborhood SES were determined to have worse all-cause survival than concordant high-SES women [23]. However, the risk was also higher among discordant SES groups (high education and low neighborhood SES) if the cases were AA or Asian American. Our study is the first to examine crosslevel effects of education and obesity on $\mathrm{CaP}$ outcomes. While other studies defined patient-level SES as education with or without income and defined neighborhood SES as a composite variable to examine cross-level effects, we focused on education discordance because of limited income data at the patient level and the fact that education may be the most valid SES factor for this patient population. 
Table 1 Education discordance groups (patient education-neighborhood education): demographics $(n=746)$

\begin{tabular}{|c|c|c|c|c|c|}
\hline Group & Patient characteristics & $\begin{array}{l}\text { Total sample } \\
n=746\end{array}$ & $\begin{array}{l}\text { Non-obese } \\
n=519 \\
(69.6 \%)\end{array}$ & $\begin{array}{l}\text { Obese } \\
n=227 \\
(30.4 \%)\end{array}$ & $\begin{array}{l}p \text { value for } \\
\text { non-obese-obese } \\
\text { comparisons }\end{array}$ \\
\hline \multirow{11}{*}{$\begin{array}{l}\text { All SCORE prostate } \\
\text { cancer cases }\end{array}$} & Median age (year) & 59 & 59 & 58 & 0.268 \\
\hline & $\%$ Married & 645 (86.7) & 454 (87.8) & $191(84.1)$ & 0.174 \\
\hline & $\%$ African-American & $104(13.9)$ & $59(11.4)$ & $45(19.8)$ & 0.002 \\
\hline & $\%$ College Education & $513(68.8)$ & $370(71.3)$ & $143(63.0)$ & 0.024 \\
\hline & $\%$ Ever smokers & $375(50.4)$ & $260(50.2)$ & $115(50.9)$ & 0.862 \\
\hline & Median BMI (kg/m2) & 27.9 & 26.5 & 32.5 & $<0.001$ \\
\hline & Median PSA ng/ml & 5.2 & 5.3 & 4.9 & 0.006 \\
\hline & $\%$ PSA > $10 \mathrm{ng} / \mathrm{ml}$ & $83(11.3)$ & $64(12.5)$ & $19(8.4)$ & 0.109 \\
\hline & $\%$ High stage (T3, T4) & $202(27.2)$ & $124(24.0)$ & $78(34.5)$ & 0.003 \\
\hline & $\%$ High grade $(7+)$ & $348(46.7)$ & $224(43.2)$ & $124(54.6)$ & 0.004 \\
\hline & & $\begin{array}{l}\text { Total } \\
n=164\end{array}$ & $\begin{array}{l}\text { Non-obese } \\
n=101 \\
(61.6 \%)\end{array}$ & $\begin{array}{l}\text { Obese } n=63 \\
(38.4 \%)\end{array}$ & $\begin{array}{l}p \text { value for } \\
\text { non-obese-obese } \\
\text { comparisons }\end{array}$ \\
\hline \multirow[t]{10}{*}{ Concordant Low-Low } & Median age (year) & 58 & 58 & 59 & 0.626 \\
\hline & $\%$ Married & $137(83.5)$ & $84(83.2)$ & $53(84.1)$ & 0.174 \\
\hline & $\%$ African-American & $44(26.8)$ & $26(25.7)$ & $18(28.6)$ & 0.691 \\
\hline & $\%$ Ever smokers & $100(61.0)$ & $58(57.4)$ & $42(66.7)$ & 0.238 \\
\hline & Median BMI (kg/m2) & 28.6 & 26.5 & 32.1 & $<0.001$ \\
\hline & Median PSA & 5.1 & 5.4 & 4.8 & 0.168 \\
\hline & $\%$ PSA $>10 \mathrm{ng} / \mathrm{ml}$ at diagnosis & $19(11.7)$ & $14(14.1)$ & $5(7.9)$ & 0.231 \\
\hline & \% High stage (T3, T4) & $49(29.9)$ & $25(24.8)$ & $24(38.1)$ & 0.069 \\
\hline & $\%$ High grade $(7+)$ & $82(50.0)$ & $51(50.5)$ & $31(49.2)$ & 0.872 \\
\hline & & $\begin{array}{l}\text { Total } \\
n=326\end{array}$ & $\begin{array}{l}\text { Non-obese } \\
n=250 \\
(76.7 \%)\end{array}$ & $\begin{array}{l}\text { Obese } \\
n=76 \\
(23.3 \%)\end{array}$ & $\begin{array}{l}p \text { value for } \\
\text { non-obese-obese } \\
\text { comparisons }\end{array}$ \\
\hline \multirow[t]{10}{*}{ Concordant High-High } & Median age (year) & 60 & 60 & 59 & 0.199 \\
\hline & $\%$ Married & $285(87.4)$ & $223(89.2)$ & $62(81.6)$ & 0.079 \\
\hline & $\%$ African-American & $22(6.8)$ & $13(5.2)$ & $9(11.8)$ & 0.043 \\
\hline & $\%$ Ever smokers & $147(45.2)$ & $118(47.4)$ & $29(38.2)$ & 0.157 \\
\hline & Median BMI (kg/m2) & 27.7 & 26.5 & 32.7 & $<0.001$ \\
\hline & Median PSA ng/ml & 5.3 & 5.4 & 5.0 & 0.044 \\
\hline & $\%$ PSA > $10 \mathrm{ng} / \mathrm{ml}$ & $39(12.1)$ & 33 (13.4) & $6(8.0)$ & 0.213 \\
\hline & \% High stage (T3, T4) & $84(25.9)$ & $59(23.7)$ & $25(33.3)$ & 0.095 \\
\hline & $\%$ High grade $(7+)$ & $153(46.9)$ & $112(44.8)$ & $41(54.0)$ & 0.162 \\
\hline & & $\begin{array}{l}\text { Total } \\
n=69\end{array}$ & $\begin{array}{l}\text { Non-obese } \\
n=48 \\
(69.6 \%)\end{array}$ & $\begin{array}{l}\text { Obese } \\
n=21 \\
(30.4 \%)\end{array}$ & $\begin{array}{l}p \text { value for } \\
\text { non-obese-obese } \\
\text { comparisons }\end{array}$ \\
\hline \multirow{9}{*}{$\begin{array}{l}\text { Discordant Low-High } \\
\text { (patient level } \\
<\text { neighborhood) }\end{array}$} & Median age (year) & 58 & 58.5 & 57 & 0.734 \\
\hline & $\%$ Married & $63(94.0)$ & $42(91.3)$ & $21(100.0)$ & $0.301 *$ \\
\hline & $\%$ African-American & $7(10.1)$ & $6(12.5)$ & $1(4.8)$ & 0.427 \\
\hline & $\%$ Ever smokers & $46(66.7)$ & $30(62.5)$ & $16(76.2)$ & 0.267 \\
\hline & Median BMI (kg/m2) & 27.3 & 26.4 & 33.1 & $<0.001$ \\
\hline & Median PSA ng/ml & 5.1 & 5.1 & 5.6 & 0.809 \\
\hline & $\%$ PSA > $10 \mathrm{ng} / \mathrm{ml}$ & $9(11.8)$ & $4(8.3)$ & $4(20.0)$ & $0.221 *$ \\
\hline & $\%$ High stage $(\mathrm{T} 3, \mathrm{~T} 4)$ & $19(27.5)$ & $13(27.1)$ & $6(28.6)$ & 0.899 \\
\hline & $\%$ High grade $(7+)$ & $33(47.8)$ & $21(43.8)$ & $12(57.1)$ & 0.305 \\
\hline
\end{tabular}


Table 1 continued

\begin{tabular}{|c|c|c|c|c|c|}
\hline & & $\begin{array}{l}\text { Total } \\
n=187\end{array}$ & $\begin{array}{l}\text { Non-obese } \\
n=120 \\
(64.2 \%)\end{array}$ & $\begin{array}{l}\text { Obese } \\
n=67 \\
(35.8 \%)\end{array}$ & $\begin{array}{l}p \text { value for } \\
\text { non-obese-obese } \\
\text { comparisons }\end{array}$ \\
\hline \multirow{9}{*}{$\begin{array}{l}\text { Discordant High-Low } \\
\text { (patient level }>\text { neighborhood) }\end{array}$} & Median age (year) & 58 & 58 & 58 & 0.825 \\
\hline & $\%$ Married & $160(85.6)$ & $105(87.5)$ & $55(82.1)$ & 0.313 \\
\hline & $\%$ African-American & $31(16.6)$ & $14(11.7)$ & $17(25.4)$ & 0.016 \\
\hline & $\%$ Ever smokers & $82(44.1)$ & $54(45.0)$ & $28(42.2)$ & 0.735 \\
\hline & Median BMI (kg/m2) & 28.3 & 26.8 & 32.4 & $<0.001$ \\
\hline & Median PSA ng/ml & 5.0 & 5.1 & 4.9 & 0.196 \\
\hline & $\%$ PSA $>10 \mathrm{ng} / \mathrm{ml}$ & $17(9.2)$ & $13(11.0)$ & $4(6.0)$ & 0.300 \\
\hline & $\%$ High stage $(\mathrm{T} 3, \mathrm{~T} 4)$ & $50(26.9)$ & $27(22.7)$ & $23(34.3)$ & 0.086 \\
\hline & $\%$ High grade $(7+)$ & $80(42.8)$ & $40(33.3)$ & $40(59.7)$ & $<0.001$ \\
\hline
\end{tabular}

* $p$ value based on Fisher's exact test when cells had sample size $\leq 5$

Bold values indicate $p<0.05$

We also examined the separate interactions of patient- and neighborhood-level education with obesity on biochemical failure. Although an increased risk for obese patients with low patient-level education was observed in those separate analyses, our study adds to the CaP literature the finding that the context in which high-risk patients live also matters. We found that only obese patients with low patient-level education living in low-education neighborhoods were at significantly increased risk of biochemical failure.

Obesity is a potentially modifiable risk factor for disease progression and poor outcomes for numerous diseases including prostate cancer. Obesity is believed to increase the risk of advanced tumor stage and grade at diagnosis, younger age at diagnosis, and biochemical failure (disease recurrence) after treatment [1-4]. However, the relationship between obesity and prostate cancer is complex. A recent large cohort study demonstrated that obesity was associated with a decreased risk of low-grade $\mathrm{CaP}$ but an increased risk of highgrade $\mathrm{CaP}$ [5]. While some previous studies did not support a relationship of obesity with $\mathrm{CaP}[3,9,11-13]$ or associations with some outcomes and not others [12], inconsistent findings may have been caused by differences in the composition of study populations, including the prevalence of obesity, ethnic distribution, nationality of the population, PSA screening recommendations in international studies, and diagnostic obstacles associated with obesity [3, 12, 27-31].

Both treatment effects and biological effects have been proposed as explanations for the effect of obesity on CaP outcomes [5, 32-35]. After prostatectomy, overweight and obese cases have significantly longer hospital stays compared with normal weight cases. Estimated blood loss during the procedure is also greater in obese and overweight cases [26]. However, potency and continence rates after treatment are similar among weight groups, so technically inferior operations do not account fully for differences in treatment failure [26]. In addition to treatment effects, numerous biological pathways have been associated with dysregulation among obese individuals, including aberrant hormone production, hormone metabolism, and alterations in insulin, insulin-like growth factor 1 (IGF-1), and leptin are well established [36-38]. Obesity also appears to promote hyperandrogenicity and presents a chronic inflammatory environment that sets the stage for cancer progression and poor prognosis, although underlying mechanisms within the tumor are poorly understood [38-42].

We focused on education as a surrogate for SES in this study, but we realize that other neighborhood and patient characteristics may contribute to the associations that we observed. Education and income (and combined metrics including both) are commonly used in the USA as measures of patient- and neighborhood-level SES [20, 22, 23]. Education is readily available in research databases and has been used in other studies of cancer outcomes [23,43]. Education is also important because it may correlate with knowledge, literacy, sense of empowerment, and skill sets that may be needed to navigate health care, decision making, and coping with disease. Although patient education is not an optimal proxy for individual SES (i.e., the same educational attainment does not result in the same societal advantage for all people or cultures), it is perhaps the best indicator to use in a population of aging men [43]. Many older men live on fixed incomes that are not reflective of their SES or accumulated wealth. Also, poor health may decrease income, but will not alter educational attainment [44]. Unlike income and occupation, educational attainment is often fixed early in 


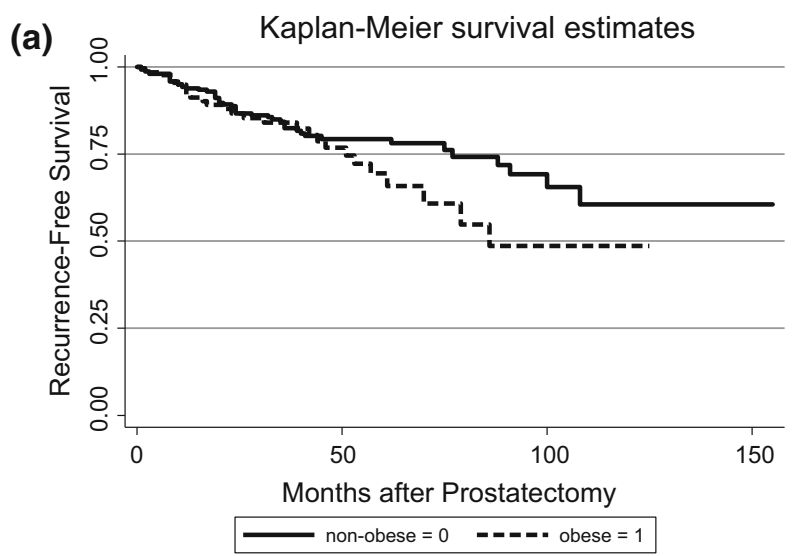

(b)

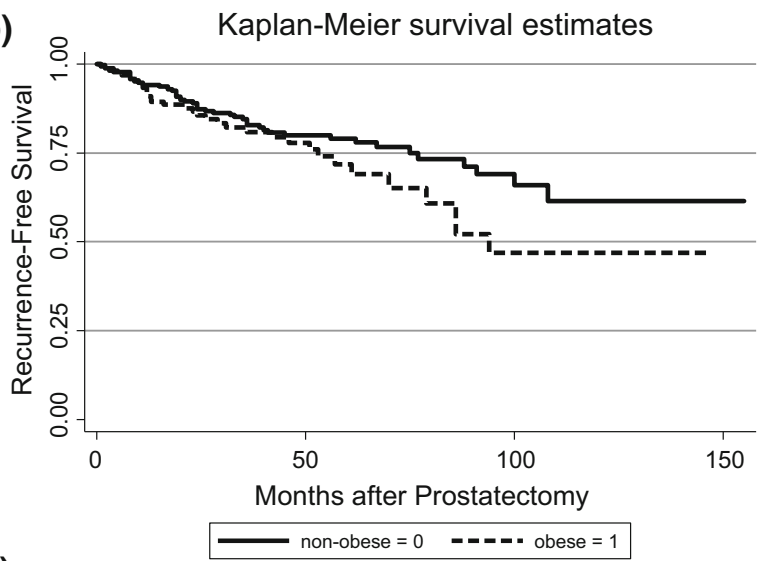

(c)

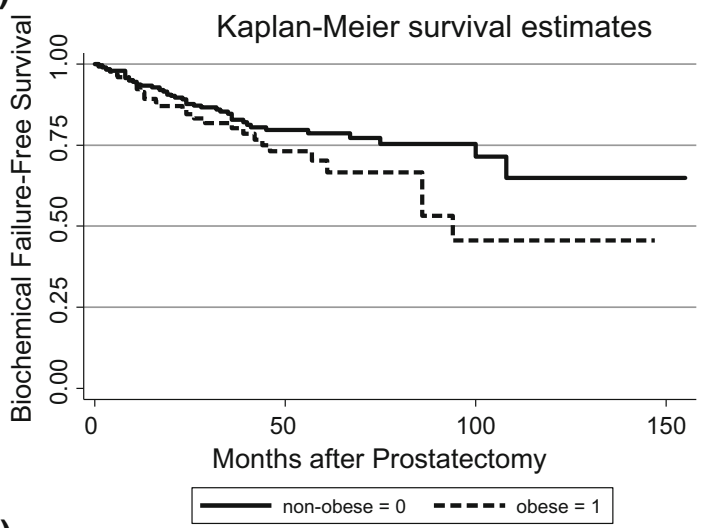

(d)

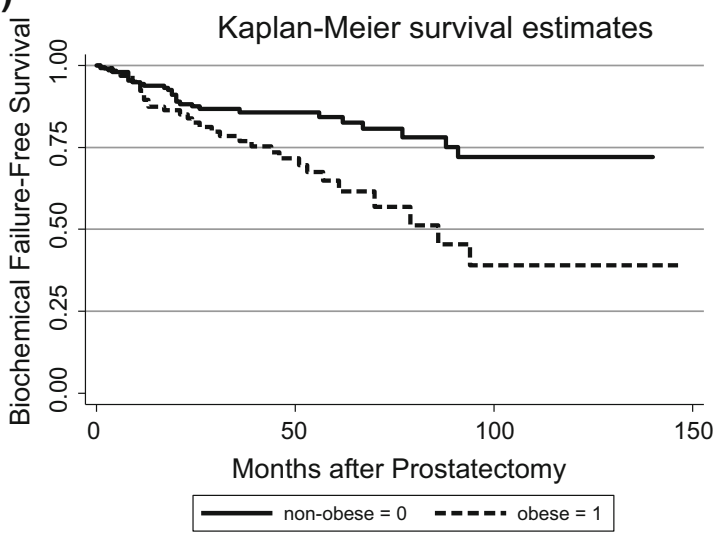

4Fig. 1 a Time to biochemical failure (Recurrence) by obesity: lower patient education, lower neighborhood education. b Time to biochemical failure (recurrence) by obesity: lower patient education, higher neighborhood education. c Time to biochemical failure (recurrence) by obesity: higher patient education, lower neighborhood education. d Time to biochemical failure (recurrence) by obesity: higher patient education, higher neighborhood education

adulthood and is less likely than income to be affected by factors such as illness, change in job, or retirement [22]. Education is also predictive of having a more favorable occupation, income, or neighborhood.

Disease risks at the individual and neighborhood level often are impacted by education. According to SEER data, higher educational attainment has been associated with greater risk of prostate and breast cancers alike. Compared to college-educated men, men with less than a college education were 0.79 as likely to be diagnosed with prostate cancer [45]. Prostate screening (and therefore CaP incidence) is more common in men with higher education, white-collar jobs, access to good health care, urban residences, and higher household income [46]. Neighborhoodlevel education also predicts metabolic syndrome independently of individual-level SES [47].

A number of limitations affect the inferences of this study. We were unable to determine length of time at reported residence and thus cannot evaluate duration of neighborhood "exposure." We do not know when neighborhood factors are most likely to contribute to cancer outcomes [43], nor do we know much what period of time is required for a particular neighborhood exposure to affect the biology of disease [48]. We began our investigation at the point of $\mathrm{CaP}$ diagnosis. This allowed us to evaluate education consistently in all cases. Another limitation of our study is the fact that the cut-points between more and less advantaged neighborhoods are arbitrary and are dependent upon our sample characteristics. We may also be limited by the "intersection of racial and SES segregation," in which relatively few AA live in the least deprived areas and few EAs live in the most deprived areas [49]. Thus, study participants are not randomly allocated into census tracts. However, we adjusted for race, age, and census tract in multivariable analysis. We also were not able to detect effects for the group that may be at highest risk: low-SES individuals residing in high-SES neighborhoods. As in other studies, this category was represented by the smallest sample size [22].

The present was ascertained from a tertiary care center, so the external validity of the results may be limited to similar hospital settings. Some cases travel from long distances to receive treatment, which means that this is also a patient group that is educated about healthcare options and has ability to travel for health care. This is also a group that tends to have medical insurance or other means of financing care. Our sample was primarily comprised of low-stage $\mathrm{CaP}$ cases $(75 \%)$ and was more educated than 
Table 2 SCORE models: relationship between obesity and prostate cancer outcomes by college concordance/discordance (patient college-neighborhood college)

\begin{tabular}{ll}
\hline Concordance/discordance group & $\begin{array}{l}\text { HR for the effect of obesity on } \\
\text { biochemical failure }(95 \% \mathrm{CI})\end{array}$ \\
\hline $\begin{array}{l}\text { Concordant-Low-Low } \\
\begin{array}{l}\text { Discordant-patient level }< \\
\text { neighborhood }\end{array}\end{array}$ & $\mathbf{3 . 7 2}(\mathbf{1 . 3 0}-\mathbf{1 0 . 6 5})$ \\
$\begin{array}{l}\text { Discordant-patient leve 1 }> \\
\text { neighborhood }\end{array}$ & $1.98(0.60-26.54)$ \\
Concordant-High-High & $0.52(0.17-1.59)$
\end{tabular}

Cox models adjusted for census tract, tumor grade, PSA at diagnosis, patient race, age, and obesity-college concordance/discordance interaction

Bold values indicate $p<0.05$

the general US population (68\% of our sample had a bachelor's degree, and our median for percent of collegeeducated residents in the surveyed census tracts was 37 vs. $29 \%$ of the US male population with college degrees). Replication studies with diverse patient populations will add external validity to the results of this study.

We chose to use census tracts as our "neighborhood" variable for this study. Although we could have used other administrative units (census blocks or zip codes), we used the most commonly utilized unit of analysis to increase comparability with other studies. Census tract boundaries are intended to combine individuals that tend to be similar with regard to social and economic characteristics. Census tracts are one of the preferred area-based units to use when attempting to capture economic deprivation. They are meaningful across regions and over time and easily understood/defined [25, 50]. Future studies may examine how cross-level effects vary by administrative unit.

\section{Conclusions}

The effects of neighborhood characteristics on the health of older men have been poorly studied. This project identified $\mathrm{CaP}$ cases and communities at highest risk of obesity, advanced cancer and poor treatment outcomes. Obese men are a high-risk group for poor prostate cancer outcomes, but not all obese men carry the same risk. Eliminating $\mathrm{CaP}$ disparities requires enhanced efforts to identify highest risk individuals. Empowering disadvantaged communities to improve aspects of the physical or social environment may be an intervention that can benefit the health of residents for years to come. While the present study does not address the mechanisms underlying the association between obesity and prostate cancer aggressiveness, research involving obese prostate cancer cases may suggest new approaches for prostate cancer intervention via weight management, physical activity, targeted screening, $\mathrm{CaP}$ education, and novel treatments.

Acknowledgments Funding for this study was awarded from the National Institutes of Health (P60-MD006900) to Dr. Rebbeck and the Department of Defense (W81XWH-14-1-0064) to Dr. ZeiglerJohnson.

\section{Compliance with Ethical Standards}

Conflicts of interest The authors declare that they have no conflict of interest.

Research Involvement of Human Participants All procedures performed in studies involving human participants were in accordance with the ethical standards of the institutional and/or national research committee and with the 1964 Helsinki declaration and its later amendments or comparable ethical standards.

Open Access This article is distributed under the terms of the Creative Commons Attribution 4.0 International License (http://crea tivecommons.org/licenses/by/4.0/), which permits unrestricted use, distribution, and reproduction in any medium, provided you give appropriate credit to the original author(s) and the source, provide a link to the Creative Commons license, and indicate if changes were made.

\section{References}

1. Spangler E, Zeigler-Johnson CM, Coomes M, Malkowicz SB, Wein A, Rebbeck TR (2007) Association of obesity with tumor characteristics and treatment failure of prostate cancer in AfricanAmerican and European American men. J Urol 178(5):1939-1944

2. Rodriguez C, Freedland S, Deka A, Jacobs E, McCullough M, Patel A, Thun M, Calle E (2007) Body mass index, weight change, and risk of prostate cancer in the cancer prevention study II nutrition cohort. Cancer Epidemiol Biomarkers Prev 161(1):63-69

3. Freedland S, Banez L, Sun L, Fitzsimons N, Moul J (2009) Obese men have higher-grade and larger tumors: an analysis of the Duke prostate center database. Prostate Cancer and Prostatic Dis 12:259-263

4. Gross M, Ramirez C, Luthringer D, Nepomuceno E, Vollmer R, Burchette J, Freedland S (2009) Expression of androgen and estrogen related proteins in normal weight and obese prostate cancer patients. Prostate 69:520-527

5. Vidal AC, Howard LE, Moreira DM, Castro-Santamaria R, Andriole GL Jr, Freedland SJ (2014) Obesity increases the risk for high-grade prostate cancer: results from the REDUCE study. Cancer Epidemiol Biomarkers Prev 23(12):2936-2942

6. Nelson MC, Gordon-Larsen P, North KE, Adair LS (2006) Body mass index gain, fast food, and physical activity: effects of shared environments over time. Obesity (Silver Spring) 14(4):701-709

7. Robert S, Reither E (2004) A multilevel analysis of race, community disadvantage, and body mass index among adults in the US. Soc Sci Med 59:2421-2434

8. Spangler E, Zeigler-Johnson CM, Coomes M, Malkowicz SB, Wein A, Rebbeck TR (2007) Association of obesity with tumor characteristics and treatment failure of prostate cancer in AfricanAmerican and European American men. J Urol 178(5):1939-1944 (discussion 1945)

9. Amling C, Riffenburgh R, Sun L, Moul J, Lance R, Kusuda L, Sexton W, Soderdahl D, Donahue T, Foley J et al (2004) Pathologic variables and recurrence rates as related to obesity and 
race in men with prostate cancer undergoing radical prostatectomy. J Clin Oncol 22(3):439-445

10. Freedland S, Terris M, Presti J Jr, Amling C, Kane C, Trock B, Aronson W, Group SDS (2004) Obesity and biochemical outcome following radical prostatectomy for organ confined disease with negative surgical margins. J Urol 172(2):520-524

11. Buschemeyer W III, Freedland S (2007) Obesity and prostate cancer: epidemiology and clinical implications. Eur Assoc Urol 52:331-343

12. Motamedina P, Korets R, Spencer B, Benson M, McKiernan J (2008) Body mass index and role of obesity in predicting outcome after radical prostatectomy. Urology 72(5):1106-1110

13. Briganti A, Karakiewicz P, Chun F-H, Suardi N, Gallina A, Abdollah F, Freschi M, Doglioni C, Rigatti P, Montorsi F (2009) Obesity does not increase the risk of lymph node metastases in patients with clinically localized prostate cancer undergoing radical prostatectomy and extended pelvic lymph node dissection. Int J Urol 16:676-681

14. Cohen D, Mason K, Bedimo A, Scribner R, Basolo V, Farley T (2003) Neighborhood physical conditions and health. Am J Public Health 93(3):467-471

15. Wardle J, Jarvis M, Steggles N, Sutton S, Williamson S, Farrimond H, Cartwright M, Simon A (2003) Socioeconomic disparities in cancer-risk behaviors in adolescence: baseline results from the health and behaviour in teenagers study (HABITS). Prev Med 36:721-730

16. Borrell L, Diex Roux A, Rose K, Catellier D, Clark B (2004) Neighborhood characteristics and mortality in the atherosclerosis risk in communities study. Int J Epidemiol 33:398-407

17. Zierler S, Krieger N, Tang Y, Coady W, Siegfried E, DeMaria A, Auerbach J (2000) Economic deprivation and AIDS incidence in Massachusetts. Am J Public Health 90(7):1064-1073

18. Winkleby M, Sundquist K, Cubbin C (2007) Inequities in CHD incidence and case fatality by neighborhood deprivation. Am $\mathrm{J}$ Prev Med 32(2):97-106

19. Cubbin C, Sundquist K, Ahlen H, Johansson S-E, Winkleby M, Sundquist J (2006) Neighborhood deprivation and cardiovascular disease risk factors: protective and harmful effects. Scand J Public Health 34:228-237

20. Winkleby M, Cubbin C, Ahn D (2006) Effect of cross-level interaction between individual and neighborhood socioeconomic status on adult mortality rates. Am J Public Health 96(12):2145-2153

21. Taylor CB, Ahn D, Winkleby MA (2006) Neighborhood and individual socioeconomic determinants of hospitalization. Am J Prev Med 31(2):127-134

22. Mulia N, Karriker-Jaffe KJ (2012) Interactive influences of neighborhood and individual socioeconomic status on alcohol consumption and problems. Alcohol Alcohol 47(2):178-186

23. Shariff-Marco S, Yang J, John EM, Sangaramoorthy M, Hertz A, Koo J, Nelson DO, Schupp CW, Shema SJ, Cockburn M et al (2014) Impact of neighborhood and individual socioeconomic status on survival after breast cancer varies by race/ethnicity: the neighborhood and breast cancer study. Cancer Epidemiol Biomarkers Prev 23(5):793-811

24. Cook WK, Mulia N, Karriker-Jaffe K (2012) Ethnic drinking cultures and alcohol use among Asian American adults: findings from a national survey. Alcohol Alcohol 47(3):340-348

25. Krieger N, Waterman P, Chen JT, Soobader MJ, Subramanian SV, Carson R (2002) Zip code caveat: bias due to spatiotemporal mismatches between zip codes and US census-defined geographic areas: the public health disparities geocoding project. Am J Public Health 92(7):1100-1102

26. Herman M, Raman J, Dong S, Samadi D, Scherr D (2007) Increasing body mass index negatively impacts outcomes following robotic radical prostatectomy. J Soc Laparoendosc Surg 11(4):438-442
27. Grubb R, Black A, Izmirlian G, Hickey T, Pinsky P, Mabie J, Riley T, Ragard L, Prorok P, Berg C et al (2009) Serum prostatespecific antigen hemodilution among obese men undergoing screening in the prostate, lung, colorectal, and ovarian cancer screening trial. Cancer Epidemiol Biomarkers Prev 18(3): 748-751

28. Rundle A, Neugut A (2009) Modeling the effects of obesity and weight gain on PSA velocity. Prostate 69:1573-1578

29. Fowke J, Matthews C (2010) PSA and body composition by dual X-ray absorptiometry (DXA) in NHANES. Prostate 70:120-125

30. Banez L, Hamilton R, Partin A, Vollmer R, Sun L, Rodriguez C, Wang Y, Terris M, Aronson W, Presti J Jr et al (2010) Obesityrelated plasma hemodilution and PSA concentration among men with prostate cancer. JAMA 298(19):2275-2280

31. Kaaks R, Stattin P (2010) Obesity, endogenous hormone metabolism, and prostate cancer risk: a conundrum of "highs" and "lows". Cancer Prev Res 3(3):279-289

32. Millender L, Aubin M, Pouliot J, Shinohara K, Roach M (2004) Daily electronic portal imaging for morbidly obese men undergoing radiotherapy for localized prostate cancer. Int $\mathrm{J}$ Radiation Oncology Biol Phys 59(1):6-10

33. Merrick G, Butler W, Wallner K, Galbreath R, Anderson R, Kurko B, Lief J (2002) Permanent prostate brachytherapy-induced morbidity in patients with grade II and III obesity. Urology 60(1):104-108

34. Rodriguez C, Freedland S, Deka A, Jacobs E, McCullough M, Patel A, Thun M, Calle E (2007) Body mass index, weight change, and risk of prostate cancer in the cancer prevention study II nutrition cohort. Cancer Epidemiol Biomarkers Prev 161(1):63-69

35. Pavelka J, Ben-Shachar I, Fowler J, Ramirez N, Copeland L, Eaton L, Manolitsas T, Cohn D (2004) Morbid obesity and endometrial cancer: surgical, clinical, and pathologic outcomes in surgically managed patients. Gynecol Oncol 95(3):588-592

36. Freedland SJ, Platz EA (2007) Obesity and prostate cancer: making sense out of apparently conflicting data. Epidemiol Rev 29:88-97

37. Wu F, von Eckardstein A (2003) Androgens and coronary artery disease. Endocr Rev 24(2):183-217

38. Li A, Elmore R, Pavelka C, Karlan B (2007) Hyperandrogenism, mediated by obesity and receptor polymorphisms, promotes aggressive epithelial ovarian cancer biology. Gynecol Oncol 107:420-423

39. Onuma M, Bub JD, Rummel TL, Iwamoto Y (2003) Prostate cancer cell-adipocyte interaction: leptin mediates androgenindependent prostate cancer cell proliferation through c-Jun NH2terminal kinase. J Biol Chem 278(43):42660-42667

40. Calle E, Kaaks R (2004) Overweight, obesity and cancer: epidemiological evidence and proposed mechanisms. Nat Rev 4:579-591

41. Weisberg S, McCann D, Desai M, Rosenbaum M, Leibel R, Ferrante A Jr (2003) Obesity is associated with macrophage accumulation in adipose tissue. J Clin Investig 112(12): 1796-1808

42. Park J, Euhus DM, Scherer PE (2011) Paracrine and endocrine effects of adipose tissue on cancer development and progression. Endocr Rev 32(4):550-570

43. Braveman PA, Cubbin C, Egerter S, Chideya S, Marchi KS, Metzler M, Posner S (2005) Socioeconomic status in health research: one size does not fit all. JAMA 294(22):2879-2888

44. Szanton S, Gill J, Allen J (2005) Allostatic load: a mechanism of socioeconomic health disparities? Biol Res Nurs 7(1):7-15

45. Clegg L, Reichman M, Miller B, Hankey B, Singh G, Lin Y, Goodman M, Lynch C, Schwartz S, Chen V et al (2009) Impact of socioeconomic status on cancer incidence and stage at diagnosis: selected findings from the surveillance, epidemiology, and 
end results: national longitudinal mortality study. Cancer Causes Control 20:417-435

46. Polasek O, Kolcic I, Voncina L, Strnad M, Vuletic S, Kern J (2007) Breast, colon, and prostate cancer in the adult population of Croatia: does rural origin matter? Rural Remote Health 7:749 (online)

47. Ngo AD, Paquet C, Howard NJ, Coffee NT, Adams R, Taylor A, Daniel M (2013) Area-level socioeconomic characteristics and incidence of metabolic syndrome: a prospective cohort study. BMC public health 13:681
48. Boardman J (2004) Stress and physical health: the role of neighborhoods as mediating and moderating mechanisms. Soc Sci Med 58(12):2473-2483

49. Messer L, Laraia B, Kaufman J, Eyster J, Holzman C, Culhane J, Elo I, Burke J, O'Campo P (2006) The development of a standard neighborhood deprivation index. J Urban Health 83(6): 1041-1062

50. Krieger N, Williams D, Moss N (1997) Measuring social class in US public health research: concepts, methodologies, and guidelines. Annu Rev Public Health 18:341-378 